4 Revised National Tuberculosis Control Programme, TB India. Social Assessment Study for RNTCP, Final Report. www.tbcindia.org/pdfs/Social\%20Assessment $\% 20$ Study $\% 20$ for $\% 20$ RNTCP\%20-\%20Final\%20Report $\% 20-\% 20$ ORG $\% 20$ CSR.pdf. Date last accessed: March 1, 2007.
5 Kapil A. The challenge of antibiotic resistance: need to contemplate. Indian J Med Res 2005; 121: 83-91.

\title{
Tracheostomy tubes are not needed for Duchenne muscular dystrophy
}

\section{To the Editors:}

Respiratory failure is the main cause of death in patients with Duchenne muscular dystrophy (DMD). Some respiratory management paradigms recommend tracheostomy for ventilator-dependent DMD patients. Prolongation of survival by years and, in many cases, decades using continuous mechanical noninvasive ventilation (NIV) without tracheostomy has been reported [1].

TOUSSAINT et al. [2] reported their experience on the use of NIV along with assisted coughing to prolong life and avoid tracheostomy for patients with DMD. However, the commentary by LOFASO et al. [3] on this outstanding work was uninformed. The commentators failed to present the outcomes of continuous NIV from other centres [4-6] and they have, apparently, no experience in continuous long-term NIV. These authors seem to be unaware that more than 250 long-term (mostly 24-h dependent) NIV users whose main interface was a simple mouthpiece during the day and a mouthpiece with a plastic phalange during sleep have been described [7]. Together, we currently have more than 1,000 continuous NIV users in our centres, some aged $>50 \mathrm{yrs}$ and most using a simple mouthpiece during daytime hours. LOFASO et al. [3] are correct to state that there are "no controlled studies that demonstrate that NIV prolongs life." The evidence to date suggests that there is no clinical equipoise regarding the use of NIV. As such, withholding such support would be unethical. LOFASO et al. [3] quote a conservative consensus statement which suggested that when NIV is inadequate "tracheostomy may be considered", but they have never reported using continuous NIV for their own patients. The recent American Thoracic Society consensus panel endorsed NIV as the therapy of choice in supporting breathing in DMD, while allowing for the possibility of tracheostomy in cases in which bulbar weakness precluded its use or expert support for NIV was unavailable locally [8]. LOFASO et al. [3] also seem to be unaware that there were signicantly fewer hospitalisations and pulmonary complications in the NIV group as compared with the tracheostomy group [9].

In reality, NIV has never been ineffective for continuous ventilatory support in competent hands unless the ventilator settings or interfaces are inadequate, patients are too mentally impaired to cooperate with it, or bulbar-innervated musculature is too impaired to protect the airway from continuous saliva aspiration that results in oxyhaemoglobin desaturation
[10]. This has not occurred in the 200 or more DMD patients managed by continuous NIV in our centres. LOFASO et al. [3] note that tracheostomy ventilation is "more effective" than NIV without ever having permitted their own patients to use long-term continuous NIV or equipped and trained them in how to avoid serious chest infections by using manually and mechanically assisted coughing when needed [5]. LOFASO et al. [3] confirmed that respiratory failure is not completely eliminated by 24-h NIV without ever discussing the cough aids that prevent it [11].

LOFASO et al. [3] state that "tracheostomy may also reduce the number of hours of ventilatory support needed per day", without understanding that DMD patients who were not using ventilators at all but are tracheotomised for acute respiratory failure often become and remain continuously ventilator dependent, whereas continuously ventilator-dependent DMD patients who are decannulated can be weaned to nocturnalonly NIV [1]. LOFASO et al. [3] would be well advised to learn why patients with tubes require more ventilatory support than NIV-managed patients [12]. They should know that patients who have used both tracheostomy and NIV ventilatory support for $\geqslant 1$ month and who are decannulated to continuous NIV unanimously prefer NIV for safety, comfort, speech, swallowing, appearance and in general [13]. Such patients often refuse to undergo tracheostomy a second time unless bulbar-innervated musculature deteriorates to the point that this becomes necessary for survival (motor neuron disease patients only) [10].

Our centres consider tracheostomy as a last resort and have been able to successfully avoid this procedure in all but a few patients, in some centres virtually never resorting to it. We would recommend that LOFASO et al. [3] try the approach for themselves before they conclude that this is neither possible nor desirable.

We disagree with the contentions that "daytime noninvasive ventilation via a mouthpiece should not be viewed as an alternative to tracheostomy" and "determining the best date for tracheostomy in patients with Duchenne muscular dystrophy remains a challenge." Indeed, instead of the latter, the challenge should be to remove tracheostomy tubes for continuous Duchenne muscular dystrophy ventilator users if the patient so desires, if there have been complications of tracheostomy, or if tube removal can facilitate social functioning like deinstitutionalisation [14]. 
J.R. Bach*, C. Bianchi" ${ }^{\#}$ J. Finder ${ }^{\top}$, T. Fragasso ${ }^{+}$, M.R. Goncalves $^{\S}$, Y. Ishikawa ${ }^{f}$, A.K. Ramlall**, D. McKim ${ }^{\# \#, ~ E . ~}$ Servera $^{\text {ฯฯ, A. Vianello }}{ }^{++}$, M. Villanova ${ }^{\S \S}$ and J.C. Winck ${ }^{\S}$

*Dept of Physical Medicine and Rehabilitation, University Hospital, Newark, NJ, and, 'Dept of Paediatrics, University of Pittsburgh, Pittsburgh, PA, USA. "Rehabilitation Dept, Sacra Famiglia Institute Foundation, Cesano Boscone, Milan, ${ }^{+}$General Intensive Care Unit, Policlinico A. Gemelli, Catholic University, Rome, ${ }^{++}$Respiratory Pathophysiology Unit, University Hospital of Padova, Padova, and, ${ }^{\S \S}$ Neuromuscular Unit, Nigrisoli Hospital, Bologna, Italy. ${ }^{\S}$ Lung Function and Rehabilitation Unit, Pulmonology Dept, University Hospital of S. João, Porto, Portugal. ${ }^{f}$ Dept of Paediatrics, National Hospital Organization Yakumo Hospital, Hokkaido, Japan. **Division of Paediatric Respirology, Alberta Children's Hospital, Calgary, Alberta, and, \#Division of Respiratory Medicine, The Rehabilitation Centre, Ottawa Hospital, Ottawa, Canada. "Rehabilitation and Ventilation Unit, Dept of Respiratory Medicine, University Hospital, Valencia, Spain.

\section{STATEMENT OF INTEREST}

None declared.

\section{REFERENCES}

1 Gomez-Merino E, Bach JR. Duchenne muscular dystrophy: prolongation of life by noninvasive ventilation and mechanically assisted coughing. Am J Phys Med Rehabil 2002; 81: 411-415.

2 Toussaint M, Steens M, Wasteels G, Soudon P. Diurnal ventilation via mouthpiece: survival in end-stage Duchenne patients. Eur Respir J 2006; 28: 549-555.

3 Lofaso F, Orlikowski D, Raphael JC. Ventilatory assistance in patients with Duchenne muscular dystrophy. Eur Respir J 2006; 28: 468-469.

4 Ishikawa Y, Bach JR, Minami R. Cardioprotection for Duchenne's muscular dystrophy. Am Heart J 1999; 137: 895-902.

5 Bach JR, Ishikawa Y, Kim H. Prevention of the pulmonary morbidity for patients with Duchenne muscular dystrophy. Chest 1997; 112: 1024-1028.

6 Servera E, Sancho J, Zafra MJ, Catala A, Vergara P, Marin J. Alternatives to endotracheal intubation for patients with neuromuscular diseases. Am J Phys Med Rehabil 2005; 84: 851-857.

7 Bach JR, Alba AS, Saporito LR. Intermittent positive pressure ventilation via the mouth as an alternative to tracheotomy for 257 ventilator users. Chest 1993; 103: 174-182.

8 Finder J, Birnkrant D, Carl J, et al. Respiratory care of the patient with Duchenne muscular dystrophy: ATS consensus statement. Am J Respir Crit Care Med 2004; 170: 456-465.

9 Respiratory muscle aids: Patient evaluation, respiratory aid protocol, and outcomes. In: Bach JR, ed. Management of Patients with Neuromuscular Disease. Philadelphia, Hanley \& Belfus, 2004; pp. 271-308.

10 Bach JR, Bianchi C, Aufiero E. Oximetry and indications for tracheotomy for amyotrophic lateral sclerosis. Chest 2004; 126: 1502-1507.
11 Bach JR. Mechanical insufflation-exsufflation: comparison of peak expiratory flows with manually assisted and unassisted coughing techniques. Chest 1993; 104: 1553-1562.

12 Home mechanical ventilation for neuromuscular ventilatory failure: conventional approaches and their outcomes. In: Bach JR, ed. Noninvasive Mechanical Ventilation. Philadelphia, Hanley \& Belfus, 2002; pp. 103-128.

13 Bach JR. A comparison of long-term ventilatory support alternatives from the perspective of the patient and care giver. Chest 1993; 104: 1702-1706.

14 Bach J, Goncalves M. Ventilator weaning by lung expansion and decannulation. Am J Phys Med Rehabil 2004; 83: 560-568.

DOI: $10.1183 / 09031936.00156806$

\section{From the authors:}

We would like to thank J.R. Bach and co-workers for their interest in our editorial. While we note their comments, our experience based on more than 500 neuromuscular patients, $60 \%$ of whom are receiving long-term noninvasive mechanical ventilation (NIMV) with manually and mechanically assisted coughing techniques [1] and $40 \%$ of whom are tracheostomised, differs from theirs.

NIMV is not always tolerated and does not avoid some severe complications, including acute respiratory failure followed by death, as observed by TOUSSAINT et al. [2] despite their undoubted competency in the field.

Our intensive care unit experience allowed us to demystify tracheostomy and to reduce tracheostomy complications. It probably explains why some patients, when asked, considered tracheostomy as a more secure ventilator interface when they had no respiratory reserve, poor tolerance of the different NIMV interfaces and/or the risk of severe complications in nonmedical settings, in particular at home. These points concur with the recent American Thoracic Society consensus [3] mentioned in the letter by J.R. Bach and co-workers. Moreover, we note that when acute respiratory failure is not present tracheostomy can be performed under local anaesthesia while the patient is undergoing noninvasive ventilation [4].

In contrast with the comments of J.R. Bach and co-workers, we believe that respiratory autonomy was better after tracheostomy, probably due to the reduction of dead space and work of breathing as we demonstrated [5]. Furthermore, we use the less resistive phonation valve [6] and try to avoid the suppression of respiratory effort in order to prevent an additional worsening of inspiratory muscle strength [7] by virtue of ventilator-induced diaphragm dysfunction. In addition, we observed improved speech after tracheostomy. This is probably due to our competency in adjusting the ventilator parameters in order to allow patients to speak [8].

The study of swallowing performance did not demonstrate a negative effect of tracheostomy [9]. Moreover, we are currently testing swallowing performances before and after tracheostomy and our first results in three patients suggest that invasive mechanical ventilation may improve swallowing efficacy 